Dermatology 2015;231:222-223

DOI: $10.1159 / 000435952$

\section{When the 'Ugly Duckling' Loses Brothers, It Becomes the 'Only Son of a Widowed Mother'}

Stefania Borsari ${ }^{\text {a }}$ Caterina Longo ${ }^{a}$, Simonetta Piana ${ }^{b}$, Elvira Moscarella a , Aimilios Lallas a , Roberto Alfanoc, Giuseppe Argenziano ${ }^{d}$

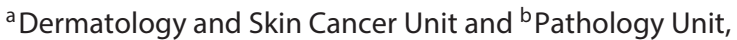
Arcispedale Santa Maria Nuova IRCCS, Reggio Emilia, and 'Department of Anesthesiology, Surgery and Emergency and ${ }^{\mathrm{d}}$ Dermatology Unit, Second University of Naples, Naples, Italy

Key Words

Melanoma Clinical diagnosis $\cdot$ Naked eye examination . Elderly subjects · Ugly duckling · Isolated lesion
Dermoscopy represents a pivotal tool for improving the clinician's sensitivity and specificity in diagnosing melanoma [1-3]. However, in some cases, the clinical, naked eye examination might be adequate per se to detect melanoma. One of the most helpful clinical criteria is the 'ugly duckling sign' [4]. The latter refers to the observation that the majority of a given individual's nevi share common morphological features (like brothers do). Instead, melanoma does not follow this 'signature pattern' and can often be diagnosed before developing evident criteria, exclusively on the basis of its different morphology, compared to the majority of the benign moles.

Since the nevus count decreases after the fourth decade of life [5], the ugly duckling sign is often not applicable to elderly patients who usually present with only few, mainly banal intradermal nevi. During our daily practice with patients over the fifth decade of life, we experienced several cases of melanoma which presented as flat, solitary lesions, dermoscopically typified by a relative lack of diagnostic clues of malignancy (fig. 1,2). Because these lesions were
Fig. 1. a, b An isolated pigmented lesion on the right arm of an 88-year-old man. c At the dermoscopic examination, a slightly irregular reticular pattern, with focal areas of hypopigmentation, can be seen.

Fig. 2. Histopathological examination of the lesion shown in figure 1 revealed a basally located intraepidermal melanocytic proliferation (a), focally arranged in confluent nests (b), suggestive of melanoma in situ.
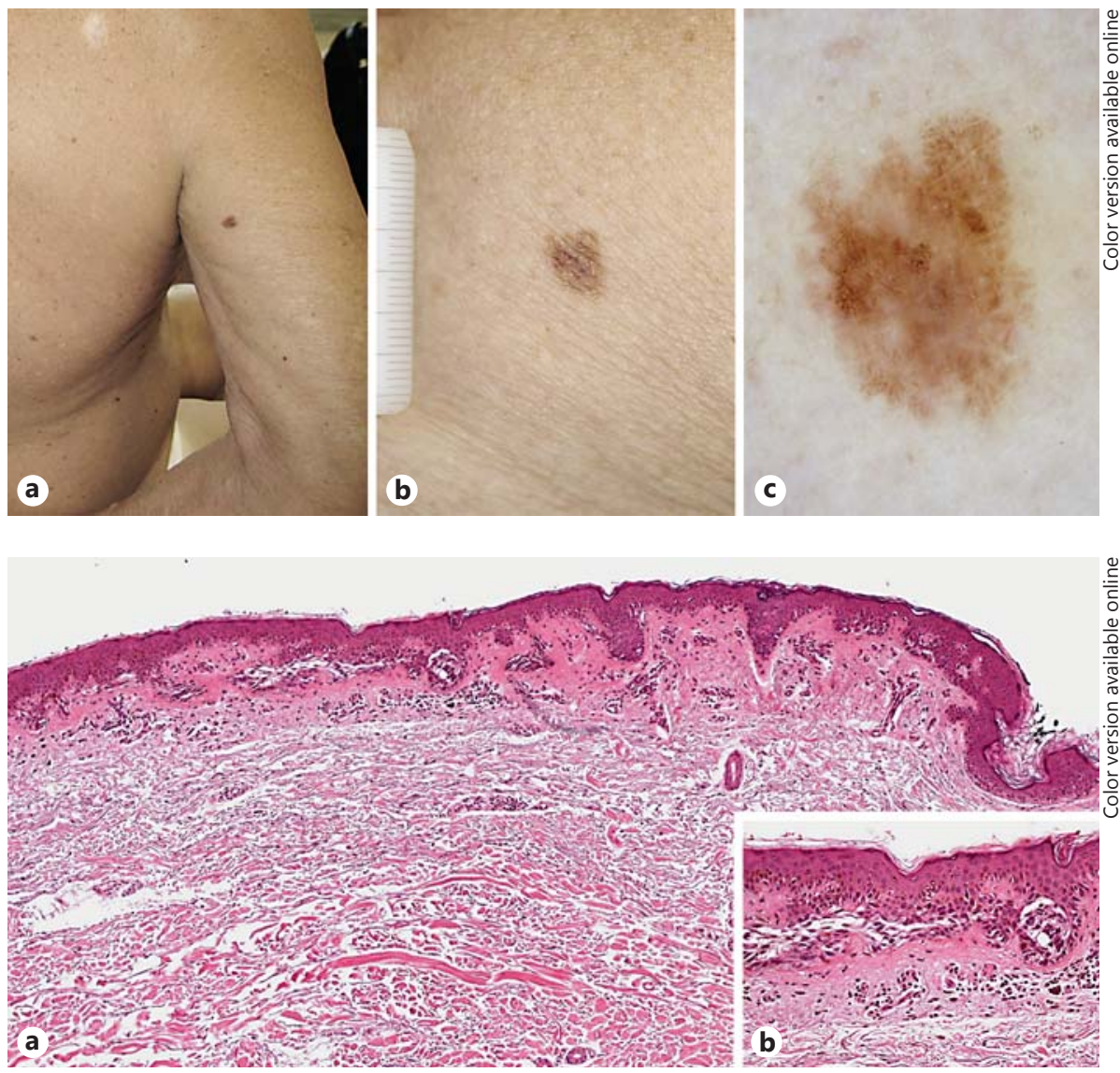

\section{KARGER 125\%}

2015 S. Karger AG, Basel $1018-8665 / 15 / 2313-0222 \$ 39.50 / 0$

E-Mail karger@karger.com www.karger.com/drm
Stefania Borsari, MD

Dermatology and Skin Cancer Unit

Arcispedale Santa Maria Nuova IRCCS, Viale Risorgimento, 80

IT-42100 Reggio Emilia (Italy)

E-Mail stefania.borsari81@gmail.com 
solitary in a given body segment, we named this criterion as the 'only son of a widowed mother', referring to an old Italian military saying, as if the ugly duckling had lost its brothers.

Aware of this new descriptor, we reviewed all melanomas diagnosed from January to December 2014 at our tertiary referral center, focusing on the main reason that led to their removal. We found that $10(6.1 \%)$ of 164 melanomas ( 8 in situ melanomas and 2 invasive melanomas with a thickness of 0.7 and $0.9 \mathrm{~mm}$ ) were removed because they were 'only sons of a widowed mother'. These 10 melanomas were found in 9 patients, 6 men and 3 women, with a mean age of 72 years. The lesions were mainly located on the limbs (8 lesions) and relatively large (diameter greater than $6 \mathrm{~mm}$ in 9 lesions), with light brown color (6 lesions), and regular pigment distribution (8 lesions). Dermoscopically, all these melanomas showed a reticular pattern, mostly characterized by a typical pigment network with regular meshes (in only 3 lesions was the network slightly focally prominent), overall not suggestive of melanoma.

As a rule, dermoscopy represents the ultimate tool to detect melanoma at an early stage, before acquiring clinically evident characteristics. However, this small series suggests that, in some cases, a clinical clue might be more useful than dermoscopic examination. In patients over 50 years of age, an acquired, flat pig- mented lesion, found as a solitary element in a given body segment, and dermoscopically typified by a reticular pattern, should be carefully evaluated and eventually excised to rule out melanoma, even in the absence of melanoma-specific criteria.

Disclosure Statement

All authors are without conflicts of interest to declare.

\section{References}

1 Kittler H, Pehamberger H, Wolff K, Binder M: Diagnostic accuracy of dermoscopy. Lancet Oncol 2002;3:159-165.

2 Vestergaard ME, Macaskill P, Holt PE, Menzies SW: Dermoscopy compared with naked eye examination for the diagnosis of primary melanoma: a meta-analysis of studies performed in a clinical setting. $\mathrm{Br} \mathrm{J}$ Dermatol 2008;159:669-676.

3 Bafounta ML, Beauchet A, Aegerter P, Saiag P: Is dermoscopy (epiluminescence microscopy) useful for the diagnosis of melanoma? Results of a meta-analysis using techniques adapted to the evaluation of diagnostic tests. Arch Dermatol 2001;137:1343-1350.

4 Grob JJ, Bonerandi JJ: The 'ugly duckling' sign: identification of the common characteristics of nevi in an individual as a basis for melanoma screening. Arch Dermatol 1998;134:103-104.

5 Loggie B, Ronan SG, Bean J, Das Gupta TK: Invasive cutaneous melanoma in elderly patients. Arch Dermatol 1991;127:1188-1193. 